Aus dem Bakteriologischen Laboratorium der ProvinzialHeil- und Pflegeanstalt in Freiburg i. Schl.

(Direktor: San.-Rat Dr. Buttenberg.)

\section{Ueber eine unter dem Bilde des Typhus abdominalis verlaufende Proteusinfektion mit tödlichem Ausgang.}

\section{Von C. v. Rottkay, Abteilungsarzt.}

Es ist schon längst bekannt, daß dem Bacterium vulgare (Proteus vulgaris) (Hauser) eine gewisse pathognomonische Dignität für den Menschen zukommt, daß es z. B. eine nicht unwesentliche Rolle bei Fleischvergiftungen spielt. Nicht bekannt dürfte es meines Wissens indessen sein, daß dieser Saprophyt auch imstande ist, Infektionen hervorzurufen, die klinisch und pathologisch-anatomisch das Bild eines ungemein schwer verlaufenden Typhus abdominalis darbieten können.

Es dürfte darum vielleicht nicht ganz ohne Interesse für die Typhus-Paratyphusfrage sein, wenn ich den nachfolgend beschriebenen, bakteriologisch genau untersuchten Fall zur allgemeinen Kenntnis bringe, der in der hiesigen Anstalt zur Beobachtung kam. Falles.

Zunächst einige Worte über den klinischen Verlauf des

O. H., $25 j$ jähriger Epileptiker, seit sieben Jahren in der Anstalt, bisher körperlich gesund, erkrankte am 17. Oktober 1909 plötzlich unter hohem Fieber $\left(40,4^{\circ}\right)$. Es bestand leichte Benommenheit. Kein Exanthem. Die Milz war wegen des überaus reichlich entwickelten Fettpolsters nicht einwandfrei zu palpieren, perkutorisch vergrößert.

19. Oktober. Keine Aenderung. Stärkere Benommenheit. Abends 40,3. Stull diarrhoisch, erbsensuppenartig, Stuhlausstrich auf Drigalskiplatten.

20. Oktober. Schwere Benominenheit. Fulliginöse Zunge. Koultinuierliches Fieber. Meteorismus.

Die Drigalskiplatten weisen neben zahlreichen Kolikolonien vereinzelte blaue, durchscheinende Kolonien auf, die weder mit Typhus- noch nit Paratyphus-A- und B-Serum sowie den drei Ruhrsera (ShigaKruse, Flexner und $\mathrm{Y}$ ) agglutinieren.

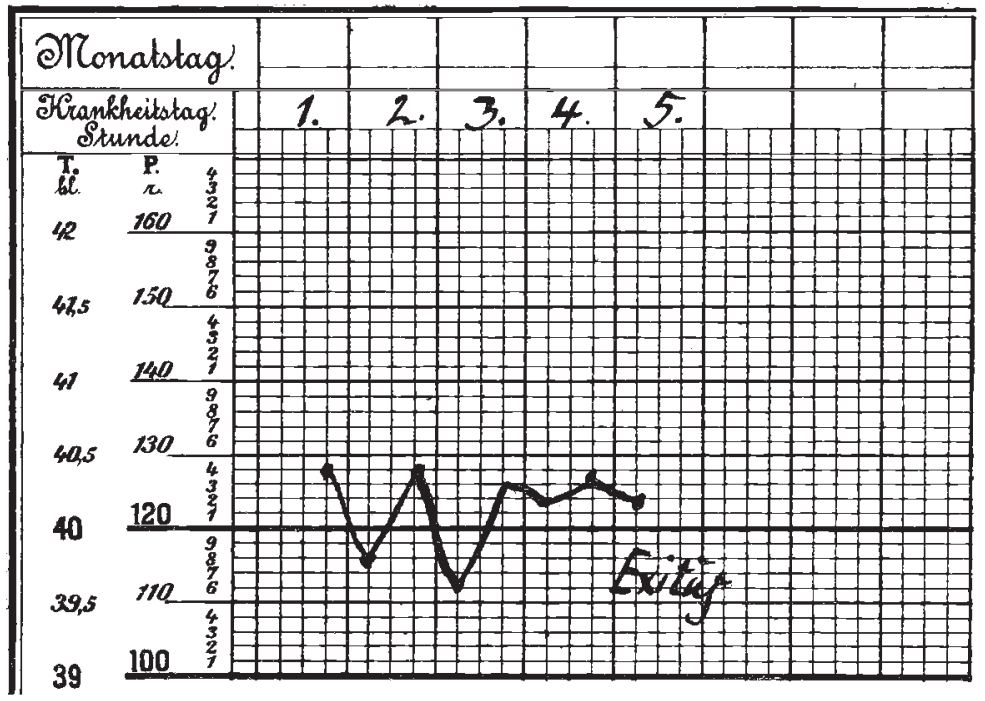

21. Oktober. Exitus letalis.

22. Oktober. Sektion ergab zahlleiche typhöse Geschwüre bzw. Infiltrationen, besonders im unteren Ileunı. Milz außerordentlich vergrößert, von fließendweicher Konsistenz.

Diagnose: Typhus abdominalis.

Da mehrere inzwischen von mir auf Neutralagar abgestrichene blaue Drigalskikolonien, auf Traubenzuckerbouillon und Neutralrotzuckeragar überimpft, starke Gasbildung, auf letzterem auch prachtvoll grüne Fluoreszenz zeigten, stellte ich die Diagnose auf Para. typhus und beschloß, wegen der fehlenden Agglutination gegen einwandsfreie Paratyphussera den Fall weiter zu verfolgen.

Es wurden demgemäß unter sterilen Kautelen geschwürige Dünndarıı- sowie Milzstücke der Leiche entnoınınen und aberınals aus diesern Material auf Drigalskiagar übergeimpft. Dabei ergab sich folgendes Resultat.

His Dilzsaftausstriche zeigten fast in Reinkultur blaue, durchsichtige Kolonien, auf einigen Platten mit ganz vereinzelten Kolikolonien vergesellschaftet, während die Ausstriche aus einem Dünndarmgeschwür das entgegengesetzte Verhalten darboten.

Von den blauen Einzelkolonien wurden wiederum je sechs Dünndarm- und je zwölf Milzsaftkolonien auf neutralen Agar übergeimpft und nach den für den Typhus bzw. Paratyphus üblichen bakteriologischbiologiselien Methoden untersucht. Da die sämtlichen Untersuchungen die gleichen biologischen Resultate ergaben, die Keime also alle als gleich anzusprechen sind, so kann die bakteriologische Beschreibung der aus verschiedenem Material gewonnenen Erreger einheitlich erfolgen.

Einschalten möchte ish noch, daß die Untersuchung des frischen Milzsaftes der Leiche im gefärbten Präparat zahlreiche Gram-negative Stäbchen zeigte. Die mikroskopische Untersuchung ines fixierten geschwürigen Dünndarmstückes, die ich der Liebenswürdigkeit des Herrn Geheimrat Prof. Dr. Ponfick in Breslau verdanke, ergab das gewöhnliche Bild des Typhus abdominalis (ausgedehnte Nekrose der Schleimhaut mit Ulzeration in der Mitte der Nekrose. Submucosa kleinzellig in filtriert, Venen stark erweitert, das ganze Gewebe verdickt und von einem dichtel Fibrinnetz erfüllt. Leukozyten meist rund-, zunı Teil gelapptkernig, zun 'Teil Kerntrümmer).

In folgenden das Ergebnis meiner balsteriologischen Untersucliungen an über 20 verschiedenen Reinkulturen aus Dünndarm und Milzsaft der Leiche, sowie aus Herzblut und Milzsaft von Versuchstieren (weißen Mäusen).

Mikroskopisches Aussehen: Stäbchen mit leicht abgerundeten Ecken. Größe nicht so stark wechselnd wie beim Proteus vulgaris der Autoren. Fadenbildung. Letztere nach längerer Fortzüchtung nicht melır vorhanden. Eigenbewegung leblhaft. Färbung: mit allen Anilinfarbstoffen gut. Gram-negativ.

Wachstum: Wächst aërob und anaërob. Bei BrutsclıranktenıperaturWachstumsoptimum, wächst aber auch bei Zimmertemperatur.

Gelatinestich: Bei $10 \%$ iger Gelatine Verflüssigung innerhalb 24 Stunden an der Oberfläche bis an den Glasrand, zylinderförmig nach unten fortschreitend. Verflüssigte Gelatine ist klar, Flocken am Boden. Der Stich selbst zeigt zahlreiche baumartige Verästelungen und Ausläufer, das Ende des Stiches knopfförmig. Im Laufe von etwa 14 Tagen wird die Kontinuität des Stiches am unteren Teile unterbrochen. Es schnüren sich flocken- und knäuelförmig Einzelkolonien ab, die alle von einem gemeinsamen liellen, fortdurchscheinenden Verflüssigungshof umgeben sind.

In höherprozentiger Gelatine geht die Verflüssigung langsamer vor sich, zunächst zylinderförmig, dann trichterförmig in die Tiefe fortschreitend. Der Stich selbst bleibt homogen ohne Ausläufer und Verästelungen, zeigt aber an seinem unteren Ende zierliche, bandartige, guirlanden-und knäuelförmige Verschlingungen, eingesäumt von einer hellen, zarteren Verflüssigungszone. Nach etwa drei Wochen dicker, körniger Endknopf, der im Verein mit dem trichterförmigen Tiefenwaclıstum der Gelatinestichkultur das Aussehen eines umgestülpten Pilzes verleiht.

Gelatineplatte: Nach zwölf Stunden zeigen einzelne Kolonien wurstförmige, gewundene Zoogloeaformen, die an Bacteriun Zopfii erinnern. Nach etwa 20 Stunden Schwärmkolonien. Pseudopodienartige, sich fortwährend ändernde Fortsätze treten aus den Kolonien heraus in die umgebende Gelatine, schnüren sich ab und wandern meist bogenförmig weiter. Verflüssigung der ganzen Platte nach etwa 30 Stunden vollkommen.

Im Gelatinestrich rasche Verflüssigung. Abrutschen der Schräg. schicht nach knapp 24 Stunden.

Agarstrich: fettiger, kräftiger, irisierender Belag.

Die Agarplatte bietet ein ähnliches, aber nicht ganz so charakteristisches Verlaalten dar wie die Gelatineplatte.

Agarsticlı: Kolonien in der Umgebung außerhalb des Stiches und Gasbildung.

Bouillonkultur: Zunächst gleichmäßige Trübung, dann Flöckchensenkung. Keine Häutchenbildung. Kein Indol. Kein Nitrit. Die Bouillon wird stark alkalisch und dunkel bernsteingelb gefärbt.

Die Blutserumplatte wird stark unter Fäulnisgeruch verflüssigt.

Milch: Nacl etwa 24 Stunden beginnt ohne vorherige Koagulation Kaseinverflüssigung bei stark alkalischer Reaktion, die auch nach vier Wochen nocl vorhanden ist, wenn bereits der größte Teil des Milcheiweißes der Auflösung verfallen ist. Heftiger Gestank.

Eijkmanscher Magermilchagar zeigt die charakteristischen lıellen Verflüssigungshöfe um die einzelnen Kolonien herum.

Neutralrotzuckeragar ist nach zehn Stunden bereits durch große Gasblasen zerrissen und zeigt prachtvoll grüne Fluoreszenz. Nach 24 Stunden wird er allmählich bis zur Agareigenfarbe entfärbt. Nach einigen Tagen kehrt dann die rote Farbe wieder.

Lackmusmolke nach 24 Stunden stark sauer, wird nach etwa 30 Stunden alkalisch und im Laufe der nächsten Tage und Wochen tiefdunkelblau, bleibt klar.

Auf Drigalskiagar zarte blaue, durchsichtige Kolonien.

Traubenzuckerbouillon zeigt nacl zehn bis zwölf Stunden starke Gasbildung, Milchzuckerbouillon auch nach tagelangern Brutschrankaufenthalt keine Vergärung, wird stark alkalisch. 
Barsiekowsche Nährböden bei $37^{\circ}$.

\begin{tabular}{|c|c|c|c|c|c|c|c|c|}
\hline & \multicolumn{8}{|c|}{ Beobachtung nach Tagen } \\
\hline & 1. & 2. & 3. & 4. & 5. & 6. & 7. & 8. \\
\hline Traubenzucker. . & $\begin{array}{l}\text { stark } \\
\text { sauer }\end{array}$ & & & & & & & \\
\hline Milchzucker ... & alkal. & $\underset{+}{\operatorname{alkal}}$ & alkal. & alkal. & alkal. & alkal. & alkal. & alkal \\
\hline $\begin{array}{l}\text { Lăvulose } \ldots . \\
\text { Saccharose . . . }\end{array}$ & $\begin{array}{c}\text { stark } \\
\text { sauer } \\
- \\
\text { schwach } \\
\text { sauer }\end{array}$ & $\begin{array}{c}\text { stark } \\
\text { sauer } \\
++ \\
\text { stark } \\
\text { sauer }\end{array}$ & & & & & & \\
\hline Saccharose ... & $\begin{array}{c}\text { sauer } \\
-\overrightarrow{\text { schwach }}\end{array}$ & sauer & schwach & schwach & stark & $\underset{\text { stark }}{ \pm}$ & $\underset{\text { stark }}{ \pm}$ & $\begin{array}{c}\text { 上 } \\
\text { stark }\end{array}$ \\
\hline Maltose .... & $\begin{array}{c}\text { sauer } \\
\text { schwach } \\
\text { sauer } \\
+ \\
\text { stark } \\
\text { saner }\end{array}$ & $\begin{array}{l}\text { sauer } \\
\text { stark } \\
\text { sauer }\end{array}$ & $\begin{array}{l}\text { sauter } \\
+ \\
\text { stark } \\
\text { sauer }\end{array}$ & & & sauer & & \\
\hline
\end{tabular}

+ völlige Nutroseausfällung, wobei die Kultur aus dem Brutschrank entfernt wurde, --.. Ausbleiben der Gerinnungsreaktion.

Stinkende Gase werden besonders in Milch, Blutserum, weniger stark auf Agar gebildet, Geruch nach Trimethylamin.

Was den Tierversuch anlangt, so wurden weiße Mäuse, mit $0,5 \mathrm{ccm} 24$ stündiger Bouillonkultur intraperitoneal injiziert, innerhalb sechs Stunden durch schwere Infektion getötet. Aus Herzblut und Milzsaft ließen sich die gleichen Bakterien züchten. Durch subkutane Impfung einer Oese Bakterienmaterial, was allerdings schon zwei Monate auf künstlichen Nährböden weitergezüchtet war und darum wohl an Virulenz erheblich eingebüßt hatte, erkrankten die Tiere zwar deutlich, aber es gelang nicht, sie dadurch zu töten.

Weitere Untersuchungen mit Kulturen, die durch Tierpassage gewonnen wurden, sind im Gange.

Nach der obigen Darstellung steht es außer Frage, daß es sich bei dem beschriebenen Bacterium um einen Angehörigen der Proteus-Klasse handelt, der aber in gewissen biologischen Eigenschaften (Gelatinestich, Wachstum in Milch und auf Blutserum, sowie insbesondere mit Bezug auf die Säuerung der einzelnen Zuckerarten bzw. höherwertigen Alkohole) von den bisher beschriebenen Stämmen abweicht. Ich habe darum die bakteriologische Beschreibung etwas eingehender gestaltet.

Daß es sich nun tatsächlich um den Erreger der schweren typhösen Erkrankung handelt, dafür spricht mir, obwohl ich mir der Schwierigkeiten der Bewertung rein bazillärer Befunde für die Aetiologie einer Erkrankung vollauf bewußt bin, einerseits dessen Gewinnung aus den Dünndarmgeschwüren sowie aus der Milz der Leiche, in letzterer, wie schon hervorgehoben, fast in Reinkultur, anderseits die Tatsache, daß durch künstliche Impfung bei Versuchstieren tödlich verlaufende Infektion hervorgerufen werden konnte. Es handelt sich also hier um eine Infektion mit einem Bacterium der Proteusgruppe.

Da die Sektion bei kalter Jahreszeit etwa zwölf Stunden post mortem erfolgte, so erscheint mir auch ein eventueller Einwand, daß das Bacterium etwa nachträglich in die Milz etc. eingewandert sein könnte, nicht stichhaltig.

Vielleicht handelt es sich um eine Mischinfektion mit Bacterium coli und dem genannten Erreger, wie solche ja schon wiederholt beschrieben worden sind; es könnte das Vorhandensein einiger Kolikolonien im Milzsaftausstrich dafür sprechen. Indessen glaube ich nicht fehlzugehen, wenn ich den Hauptanteil an der schweren letalen Infektion dem beschriebenen Bacteriun zuweise. Inwieweit dabei die Infektion als solche, inwieweit Vergiftung durch Bakterientoxine eine Rolle spielen, lasse ich dahingestellt.

Die Aetiologie des Falles ist leider ungeklärt geblieben. Am wahrscheinlichsten ist mir eine Infektion durch Fleisch, die möglicherweise außerhalb der Anstalt erfolgt ist, da der Kranke kurz vor der Erkrankung von einem 14tägigen Urlaub zurückgekehrt war. Hervorheben möchte ich noch, daß Typhusbazillen trotz sorgfältigster und umfassender darauf gerichteter Untersuchungen nicht gefunden werden konnten. Auch möchte ich noch zum Schlusse darauf hinweisen, daß der Fall völlig vereinzelt blieb und jetzt, nach Verlauf von über zwei Monaten, keine weitere ähnliche Infektion in der Anstalt erfolgt ist.
Schluß. Jedenfalls ist es nicht uninteressant und erscheint mir bei der Würdigung der Aetiologie typhöser Erkrankungen nicht unwichtig, daß bei einem Falle, der pathologisch-anatomisch das typische Bild des Typhus abdominalis darbot, ein Bacillus als Erreger gefunden werden konnte, der weder der Typhus- noch der Paratyphusgruppe angehört, sondern sich als ein, allerdings von den bisher beschriebenen Formen in gewissen Beziehungen biologisch abweichender Keim aus. der Familie des Proteus präsentiert. 